\title{
Mayaro fever: molecular diagnosis of 5 cases in Mato Grosso state
}

\begin{abstract}
Mayaro fever is an arboviroses which can be assymptomatic or progress to acute febrile disease, and may cause long-term arthritis. It is common in flrestal areas, however there are some discriotions axons urban location, and it is responsible for $1 \%$ of dengue-like cases on endemic DenV regions. Moreover, previous assays could identify MayV in mosquitoes. In this report case, during the recruting of chikungunya patients, it was observed 5 cases of patients with Mayaro acute infection, detected by RT-PCR, and they have been submitted to treatment of viral arthritis
\end{abstract}

Keywords: mayaro fever, febrile disease, MAYV infection, Mato Grosso state, chikungunya patients, arboviroses

\author{
Volume 9 Issue 2 - 202| \\ Matheus Yung Perin,' Maíra Sant Anna \\ Genaro, ${ }^{2}$ Isabelle Silva Côsso, ${ }^{2}$ Renata \\ Desengrini Slhessarenko ${ }^{3}$ \\ IMedcine Resident at Hospital São Mateus, Brazil \\ ${ }^{2}$ Doctor At Universidade de Cuiabá, Brazil \\ ${ }^{3}$ Department of Virology, Universidade de Federal de Mato \\ Grosso, Brazil
} Correspondence: Matheus Yung Perin, Medcine Resident at
Hospital São Mateus, Brazil,Tel +55 $6699908-9093$,

Emailmatheusyungperin@gmail.com

Received: May 17, 2021 | Published: May 26, 2021

\section{Introduction}

Mayaro Virus (MAYV) is an arthritogenic Alphavirus belonging to family Togaviridae. MAYV infection may be asymptomatic or progress to acute febrile disease, frequently accompanied by long-term arthritis and skin rash; similarly, to other Semiliki Forest members as Chiungunya virus (CHIKV) ${ }^{1,2}$ This virus is responsible for febrile disease in Northern South America, especially in the Amazon and Central America, affecting people who work or live near forest areas. It is estimated that $1 \%$ of all the dengue-like fever in these regions is cause by MAYV. ${ }^{2,3}$ MAYV is maintained in enzootic and rural cycles of transmission involving mainly Haemagogus janthinomys, a treedwelling primary vector, birds and monkeys as hosts and humans as accidental hosts. Other mosquitoes have been implicated in natural and experimental transmission as secondary vectors, e.g. Anopheles sp., Coquillettidia venezuelensis, Psorophora ferox, Culex sp. and Sabethes sp., as well as Aedes albopictus, Aedes serratus and Aedes aegypti. ${ }^{2,3}$ However, the most expressive number of MAYV occurrence has been reported in Brazilian North Region, on Pará ${ }^{4,5}$ and Amazonas ${ }^{6}$ States, both in humans and mosquitoes analysis. In Mato Grosso, the largest Amazonia State, there have been reports among native Xavante Indians ${ }^{7}$, and, nowadays, in mosquitoes and human serum sample, the MAYV could be isolated, especially during arbovirus outbreak. ${ }^{8}$ The virus circulation has been documented in other studies from now on; all the drafts had its period of material collect during the rainy period in Mato Grosso. ${ }^{9-12}$ This document is the report of five chronic articular cases post-Mayaro fever in patients receiving clinical care at the Chikungunya ambulatory, Cuiabá University (UNIC) from Mato Grosso, Midwestern Brazil. This study follows the recommendations of Brazilian Ministry of Health (CNS) resolution 466/2012 and was previously approved by the UFMT health ethics committee (number 2.658.648).

\section{Methods}

This text is part of an essay about Chikungunya fever, approved by ethics committee, in which some patients, during the acute period of the disease, seek medical assistance in our ambulatory. There, they have always been informed about the clinical research and then, those who agreed, signed a Free informed Consent. During the acute period, it has been collected a sample of peripheral blood of each patient and then, a new appointment was scheduled. Five patients were included in this study, however, two of them never returned to the research ambulatory for the scheduled consultation; they have only made their serum available for the trial. One of the 3 patients' blood samples had already been sent to the Public Central Health Laboratory of Mato Grosso (LACEN-MT) and it was submitted to ELISA to identify the Chikungunya antibody, while the other 2 samples only provided the molecular diagnosis. Both owners of the 2 samples agreed to undergo an articular biopsy.

\section{Obtaining and molecular analysis of the serum}

After garroting a patient's arm, under aseptic technique, a vein puncture was performed, especially on brachial vein, to obtain $5 \mathrm{~mL}$ of blood. The blood sample was stored in tubes without anticoagulant. The collected blood was centrifuged for 10 minutes by $3000 \mathrm{rpm}$ on Eppendorf Centrifuge $5810 \mathrm{R}^{\mathrm{TM}}$ for the separation of the serum, which was transferred to a $2.5 \mathrm{ml}$ Eppendorf ${ }^{\mathrm{TM}}$ tube, sent to the virology lab of the Universidade Federal de Mato Grosso (UFMT) and kept under $-80^{\circ} \mathrm{C}$ refrigeration.

\section{Viral RNA extraction and reverse transcription}

Viral RNA was extracted from $140 \mu \mathrm{L}$ of serum (QIAMP viral RNA mini kit, QIAGEN) and immediately reverse transcribed with genus specific primers (FG2 for a NS5 region of flaviviruses at $1,5 \mu \mathrm{M}$; $\mathrm{cM}^{3} \mathrm{~W}$ for a NsP1 region of alphaviruses at $5 \mu \mathrm{M}$ ), ZIKV NS5 region (9197 at $4 \mu \mathrm{M}, 192 \mathrm{pb})$ and CHIKV envelope region (CHIKENVR at $2 \mu \mathrm{M}, 305 \mathrm{pb}$ ), as previously described. ${ }^{8,10,13-15}$

\section{Multiplex-semi-nested PCR for nine flavivirus and four alphavirus species}

The cDNA $(8 \mu \mathrm{L})$ was subjected to a duplex-PCR for flaviviruses (primer FG1; $0.3 \mu \mathrm{M} ; 958 \mathrm{pb}$ ) and alphaviruses (primer M2W; $1 \mu \mathrm{M} ; 433 \mathrm{pb}$ ), followed by three semi-nested PCR for flavivirus 1 (DENV-1, -2, -3, yellow fever [YFV] and Saint Louis encephalitis [SLEV]), flavivirus 2 (DENV-4, Ilhéus [ILHV], Rocio [ROCV] and West Nile [WNV]) and alphavirus (Mayaro [MAYV], East, West and Venezuelan equine encephalitis [EEEV, WEEV, VEEV]) as 
previously described. ${ }^{12,13}$ Positive samples were subjected to single PCR in triplicate with the same species-specific primers for nucleotide sequencing. Positive and no template controls were included in every reaction as previously described. ${ }^{8,10}$

\section{PCR for an envelope region of CHIKV}

To amplify a region of CHIKV envelope gene (305pb), $6 \mu \mathrm{L}$ of cDNA were amplified with $0.8 \mu \mathrm{M}$ of primers CHIKF and CHIKR as described by Edwards et al. ${ }^{14}$ Positive control was a CHIKV isolate obtained from a sick monkey in previous studies from our group.

\section{Nucleotide sequencing and sequence analysis}

Positive PCR products obtained in triplicate single reactions for flaviviruses, alphaviruses and orthobunyaviruses were purified with $20 \%$ polyethileneglycol 8000 , quantified with quantifluor dsDNA kit (Quantus fluorometer, Promega) and subjected to nucleotide sequencing after Big Dye terminator amplification with the same primers used in the RT-PCR (3500 Genetic Analyser, Apllied Biosystems). Nucleotide sequences were aligned, analyzed with specific programs (Geneious R6) and compared to sequences of virus strains and isolates deposited at GenBank (PubMed, NCBI). The ZIKV and CHIKV phylogenetic trees were constructed by NeighborJoining (NJ) method, 1000 bootstrap replicates, Jones-Taylor Thornton distance. The OROV S segment phylogenetic tree was constructed using the Bayesian MCMC analysis method implemented in MrBayes (v3.2.6).

\section{Biopsy procedure}

Each of the patients who agreed was submitted to an articular biopsy. All these procedures were performed by an orthopedist, who chose the most symptomatic joint to proceed the surgery. Under sterile technique and after asepsis, a fenestrated-field was placed on the previously chosen body region. A small area around the chosen joint was anesthetized with lidocaine $2 \%$ and then performed an incision in the skin of $1.5-2 \mathrm{~cm}$, with an $\mathrm{n} .15$ blade, to expose the subcutaneous tissue. Using a curve Kelly clamp, the tissue and the tendons were divulsioned carefully to expose the articular capsule. Once visualized that structure, it was clamped with an Adson tweeze with teeth and 2 little pieces of articular capsule were collected: one of them was placed on $3 \mathrm{~mL}$ of tamponed formaldehyde $10 \%$ and sent to a histology laboratory at UFMT; the other one was placed on a $1,5 \mathrm{~mL}$ Eppendor $\mathrm{f}^{\mathrm{TM}}$ dry tube and sent to the virology lab at UFMT. After obtaining these pieces, the skin was sutured using a Mayo needle holder and nylon 6-0. A sterile bandage with gauze and microporous tape was used for the occlusive bandaging. Some anti-inflammatory pills were prescribed and provided for each patient in case of pain. The synovial tissue was fixed with paraformaldehyde $4 \%$, decalcified and embedded on a paraffin block. After these stages, the block was placed at a microtome and cut into several $4 \mu \mathrm{m}$ histologic sections, which were colored with hematoxylin and eosin. The microscope reading was used to verify the vacuoles formation, as those structures suggest viral replication; and leukocyte infiltrate.

\section{Cases report}

\section{Case I}

A 48-year-old previously healthy brown woman, from Várzea Grande, Cuiabá's neighbouring city, presented fever, headache and myalgia for 3 days; along with arthralgia in wrists, hands and ankles; showing morning stiffness. It happened on December of 2017. On physical examination (PE), there were no signs of arthritis other than pain in the right shoulder and in the $1^{\text {st }}$ metacarpophalangeal joint.
Complementary exams: negative for rheumatoid factor (RF), negative for antinuclear factor (ANF), ferritin $165 \mathrm{mg} / \mathrm{dL}, \mathrm{C}$ reactive protein (CRP) $0.23 \mathrm{mg} / \mathrm{dL}$, erythrocytes sedimentation rate (ESR) $20 \mathrm{~mm} / 1^{\mathrm{st}} \mathrm{h}$. The patient had no chikungunya serology, only dengue IgM (negative) and $\mathrm{IgG}$ positive. RT-PCR was positive for MayV. In this case, because of MayV arthropathy, it was introduced hydroxychloroquine (HCQ) $400 \mathrm{mg}$ daily. The biopsy suggests viral presence and inflammatory process due to the presence of histocytes, lymphocytes and cells with large nucleus rounded by vacuoles, probably macrophages in activity; also, heterogeneous extracellular matrix suggests chronic degradation. However, the PCR could not demonstrate viral RNA in the specimen. After 3 months, the patient reported a considerable improvement in pain. There were no findings on physical examination. Lab exams showed ferritin $163.99 \mathrm{mg} / \mathrm{dL}$, CRP $0.54 \mathrm{mg} / \mathrm{dL}$ and ESR $5 \mathrm{~mm} / 1^{\text {st }}$. We kept the therapy and scheduled a return in 3 months. In the $6^{\text {th }}$ month, methotrexate (MTX) was introduced to the treatment due to pain complaints and painful reaction during PE. By the $9^{\text {th }}$ month, the patient had stopped taking the MTX on her own, because she had been asymptomatic and did not tolerate the drug.

\section{Case 2}

A 50-year-old previously healthy brown woman, on December of 2017, presented pain in her left ankle with progressive worsening, associated with fever, asthenia, morning stiffness, pruritus rash and arthralgia in her left ankle, knees, shoulders and various interphalangeal joints of the hand. By PE: no sign of arthritis, besides pain during palpation in all interphalangeal joints, Heberden's nodules and crackling of both knees. Lab exams: CPR $0.24 \mathrm{mg} / \mathrm{dL}$, ESR $50 \mathrm{~mm} / 1^{\text {st }} \mathrm{h}$, negative for RF, negative for ANF. During the first consultations, the diagnostic hypothesis was osteoarthritis (OA) in hands and knees, fibromyalgia, and ChikV arthropathy. Intramuscular betamethasone dipropionate $5 \mathrm{mg}+$ betamethasone sodium phosphate $2 \mathrm{mg}$ in unique administration, and glucosamine $1.5 \mathrm{~g}+$ chondroitin $1.2 \mathrm{~g}$ were prescribed. However, on the $3^{\text {rd }}$ moth, the RT-PCR results, confirmed only MayV in serum. The patient has kept the reports on articular pain and swelling, with more than 1 hour morning stiffness in foot, ankle, hands and wrists, presenting negative serology for ChikV $\operatorname{IgM}(0.3)$ and positive for $\operatorname{IgG}(4.3)$. Moreover, ferritin $188.56 \mathrm{mg} /$ $\mathrm{dL}, \mathrm{CPR} 1.73 \mathrm{mg} / \mathrm{dL}$, ERS $60 \mathrm{~mm} / 1^{\mathrm{sth}}$. As we could not find RNA ChikV in collected blood, ChikV arthropathy was discarded (CA). MayV arthropathy (MA) was the only match. At this moment, we have started the graduation of MTX $15 \mathrm{mg}$ in $10 \mathrm{mg}$ every 2 weeks up to $25 \mathrm{mg}$, once a week, and folic acid $5 \mathrm{mg}$ to be taken the day after MTX, once a week; also anthelmintic and vaccination.

\section{Case 3}

A 62-year-old brown woman, from Várzea Grande, previously hipertensive, in use of losartan $100 \mathrm{mg} /$ day, propranolol $80 \mathrm{mg} /$ day, hydrochlorothiazide $25 \mathrm{mg} /$ day; rheumatic disease which she did not know the name. The anamnesis revealed arthralgia in knees and ankle with progressive worsening and morning stiffness for more than 1hour, without swelling; symptoms associated with myalgia, asthenia, fever and pruritus rash, since December 2017. The pain had improved with intramuscular corticosteroid. PE has shown Heberden's nodes in left hand and crepitation in knees with no sign of arthritis. Lab exams returned with RT-PCR results positive for MayV, negative for $\mathrm{RF}$, negative for ANF, ferritin $200 \mathrm{mg} / \mathrm{dL}$, CPR $2.33 \mathrm{mg} / \mathrm{dL}$ and ERS $50 \mathrm{~mm} / 1^{\text {sth }}$. Our diagnostic hypothesis was, besides MA, OA in knees and left hand. As therapeutic proposal, MTX 15mg once a week, folic acid $5 \mathrm{mg}$ to be taken the day after MTX, anthelmintic and vaccination. On $5^{\text {th }}$ month, the patient related some pain improvement, however it has not disappeared. By PE we could find left gluteus medius 
tendinopathy, with no sign of arthritis. Inflammatory biomarkers also presented significant relief, ferritin $161.42 \mathrm{mg} / \mathrm{dL}$, CPR $0.26 \mathrm{mg} / \mathrm{dL}$ and SSR $20 \mathrm{~mm} / 1^{\text {st }}$. Due to the pain, we decided to maintain the MTX and increase the dose to $20 \mathrm{mg} /$ week. This patient agreed to undergo an articular biopsy, which demonstrated a leukocyte infiltrate, especially macrophages with a large, vacuolized nucleus, suggesting phagocytic activity due to the presence of viruses; and abundant lymphocytes, suggesting a chronic inflammatory process. However, no viral RNA was found in specimen.

\section{Cases 4 and 5}

These patients made their blood samples available for RT-PCR analysis; however, they never returned to the ambulatory, despite telephone calls and contact attempts. Both sera presented MayV. However, we do not have the clinical history of the respective patients.

\section{Discussion}

Arthritogenic alphaviruses are arboviruses associated with acute febrile disease accompanied by intense arthritis and other clinical manifestations, which include debilitating arthralgia and rash. ${ }^{1,2}$ The acute symptoms become abruptly and last usually 3 or 5 days, and the arthralgia is most intense in small articulations. Other symptoms include myalgia, photophobia, headache, chills, epigastric pain, nausea and diffuse pain. There are, besides, descriptions related to persistence of arthritis in patients for up to 6 months. ${ }^{16,17}$ Currently, no studies have concluded the pathogenesis of MAYV infection, however, some characteristics are like the other alphaviruses. ${ }^{17}$ However, these long-term clinical presentations mimic those associated to rheumatoid arthritis (RA), including manifestations in bones, joints, tendons and other systems. ${ }^{18}$ After the inoculation of virus in subcutaneous tissue, it become the replication in lymphocytes, liver and $\operatorname{spleen}^{17}$ and then, these kind of replication in other sites, like bones, muscles and joints, and articular replications ins strongly associated with chronic inflammatory process. ${ }^{19,20}$

This chronic inflammatory process express high level of serum IL-6, and this intertokine is responsible to stimulate the release of RANKL and inhibit the osteoprotegerin, promoting the osteoclastogenesis. Therefore, the permanence of macrophages in joint and a continuously expression of IL- 6 and RANKL contributes to a permanent injury on the joints, keeping the chronic arthritis. ${ }^{20}$ All the patients had de beginning of symptoms in December 2017, and besides they had decided to begin the following in ambulatory, they do not keep a regular, as oriented each 3 months, the medical consultations. However, all the ones have more than one and half year with any symptom, besides, were prescribed drugs, according to Sociedade Brasileira de Reumatologia and Ministério da Saúde, to treat arthritis and arthropathy by alphavirus. ${ }^{21}$ All these drugs are used in RA. Because the immunopathology is similar in both situations, probably, the alphavirus induces a type of autoimmunity. ${ }^{18,21-23}$ In only one situation the patient had the molecular analysis positive to MayV, however, the serology was positive to ChikV. In this case, we could consider cross-reactivity. Probably co-infection should be considered, though, the molecular essay demonstrated just one virus, MayV in this case. Therefore, we could conclude, even though it is the unique sample among those 5 patients, that it is a cross-reaction in ELISA test. What happens because of the similarity between both virus epitopes, producing antibodies, and these are found in ELISA, what could, maybe, misdiagnosis MayV infection, and, among our patients, that we could only have the serological diagnosis, probably there are more than those 3 cases..$^{24,25}$ Moreover, our patients had three proinflammatory biomarker dosed (ERS, CPR and ferritin), in all the cases, the ferritin was normal in all those patients, this could be a potential marker, ${ }^{26}$ however other authors have not identified as a good marker, as well. 27,28

The only pro-inflammatory marker kept in higher levels were ERS, according to the patients' symptoms. Furthermore, CPR show some elevation during the acute process. Maybe, this two could be the best biomarkers for inflammatory activity, ${ }^{29,30}$ however, we depend on more studies to establish the adequate inflammatory markers. In two of the patients, we collected joint capsule specimen to histopathologic and molecular study. We could notice an inflammatory process persistence, indicated by leucocytes in the tissue, especially macrophage in activity and a large number of lymphocytes, which suggests a type of virus persistency, included inside the cell ${ }^{31}$ and a chronic process. ${ }^{20,32}$ We could not, though, find in molecular analysis of biopsy, under the technique used, any type of virus RNA. Therefore, it is still a doubt of the persistence of virus or of viral structure (e.g. capsid or another protein) which could activate macrophage activity, or persistence of virus (or its structure) inside the monocytes/ macrophages ${ }^{33}$ Furthermore, if the virus presents a type of "tropism" by osteoblasts and the virus could demonstrate a multiplicity in this kind of cell, probably the better specimen should be a bone sample to be analyzed by culture and molecular techniques. ${ }^{20,34}$ Nevertheless, we depend on other techniques, like Western blot, for example, to elucidate our questions, which would be responsible to detect proteins. ${ }^{35}$ In animal models, there are differences in acute and chronic joint tissue by pathology. Probably secondary to virus RNA which activates the immunological responses and become more severe. In histopathology, author found arthritis, synovitis and myositis, and the cell predominantly were macrophages and neutrophils. In additions, during the chronicity there are a preponderance of macrophage and lymphocytes, causing musculoskeletal alterations. Moreover, some authors suggest a pathology associated to viral RNA, thus, B and T cell could be responsible to prevent a development of more severe chronic disease. ${ }^{19,33,36}$

Our histological analysis was like the animal model documents, relative to the cell population and synovial alterations, besides the technique in animal model consider all the joint structures, includes muscle, bone, synovial liquid and space, synovial capsule. Our study had only the capsule tissue. Another essay based on synovial fluid analysis, in chronic patients, which search arthritogenic virus on that liquid, had not find any viral protein by mass spectrometry, and this study suggests an autoimmune activation, moreover, justify using HCQ and MTX. ${ }^{37}$ These types of drugs, because of the immunomodulation process, interrupt the leucocyte proliferation, especially lymphocytes and macrophages, MTX by acting on dihydrofolate reductase which block the DNA synthesis. ${ }^{38,39}$ On the other hand, HCQ increase the $\mathrm{pH}$ of intracellular vacuoles and the other process like degradation of protein inside the lysosomes, and its activity is reducing of $\mathrm{M} \mid \mathrm{HC}$ peptides formations and, consequently, its presentation to a CD4 $+\mathrm{T}$ cell, require stimulating it, performing a down-regulation on autoimmunity process. ${ }^{40,41}$

\section{Acknowledgments}

None.

\section{Conflicts of interest}

The authors declare that there is no conflict of interest.

\section{References}

1. Levi LI, Vignuzzi, M. Artrhitogenic alphaviruses: A worldwide emerging threat? Microorganism. 2019;7(5):133-158. 
2. Santos FM, Roberto Sousa Dias, Michelle Dias de Oliveira, et al. Animal model of artrhitis and myositis induced by Mayaro virus. PLos Nel Trop Dis. 2019;13(5):e0007375.

3. Mota MT de O, Milene Rocha Ribeiro, Danila Vedovello, et al. Mayaro vírus: a neglected arbovirus of the Americas. Future Virol. 2015;10(9):1109-1122.

4. Azevedo RSS, Eliana V P Silva, Valéria L Carvalho, et al. Mayaro fever virus, Brazilian Amazon. Emerg Infect Dis. 2009;15(11):1830-1832.

5. Nunes MRT, Taciana Fernandes Souza Barbosa, Lívia Medeiros Neves Casseb, et al. Eco-epidemiologia dos arbovírus na área de influência da rodovia Cuiabá- Santarém (BR 163), Estado do Pará, Brasil. Cad. Saúde Pública. 2009;25(12):2583-2602.

6. Maria Paula Gomes Mourão, Michele de Souza Bastos, Regina Pinto de Figueiredo, et al. Mayaro Fever in the ciry of Manaus, Brazil, 2007-2008. Vector-Borne and Zoonotic Diseases. 2012;12(1):42-46.

7. Neel JV, Andrade AH, Brown GE, et al. Further studies of the Xavante Indians. IX. Immunologic status with respect to various diseases and organisms. Am J Trop Med Hyg. 1968;17:486-498.

8. Zuchi N, Letícia Borges da Silva Heinen, Marcelo Adriano Mendes dos Santos, et al. Molecular detection of Mayaro virus during a dengue outbreak in the state of Mato Grosso, Central-West Brazil. Memórias do Instituto Oswaldo Cruz. 2014;109:820-823.

9. Cardoso BF, Otacília Pereira Serra, Letícia Borges da Silva Heinen, et al. Detection of Oropouche virus segment $\mathrm{S}$ in patients and in Culex quinquefasciatus in the state of Mato Grosso, Brazil. Memórias do Instituto Oswaldo Cruz. 2015;110:745-754.

10. Costa MCS, Siqueira Maia LM, Costa de Souza V, et al. Arbovirus investigation on patients from Mato Grosso During Zika and Chikungunya virus introduction in Brazil, 2015-2016. Acta Tropica. 2019;190:395-402.

11. Heinen LBS, Nayara Zuchi, Belgath Fernandes Cardoso, et al. Dengue outbreak in Mato Grosso, West-Central Brazil in 2011-2012. Revista do Instituto de Medicina Tropical de São Paulo. 2015;57:1-6.

12. Serra OP, Belgath Fernandes Cardoso, Ana Lúcia Maria Ribeiro, et al Mayaro virus and dengue virus 1 and 4 natural infection in culicids from Cuiabá, state of Mato Grosso, Brazil. Mem Inst Oswaldo Cruz. 2016;111(1):20-29.

13. Bronzoni RVM, Flávia Graciela Baleotti, Rita Maria Ribeiro Nogueira, et al. Duplex reverse transcription-PCR followed by Nested PCR assays for detection and identification of Brazilian alphaviruses and falviviruses. Journal of Clinical Microbiology. 2005;43:679-702.

14. Edwards CJ, Stephen R Welch, John Chamberlain, et al. Molecular diagnosis and analysis of Chikungunya virus. Journal of Clinical Virology. 2007;34:271-275.

15. Michelle N D Balm, Chun Kiat Lee, Hong Kai Lee, et al. A diagnostic polymerase chain reaction assay for Zika virus. Journal of Medical Virology. 2012;84:1501-1505.

16. Marie Christine Jaffar-Bandjee, Duksha Ramful, Bernard Alex Gauzere, et al. Emergence and clinical insights into the pathology of Chikungunya vuirus infection. Expert Rev Infect Ther. 2010;8(9):987-996.

17. Napoleão-Pego P, Luciano Pinto Gomes, 2 David William Provance Jr, et al. Mayaro virus disease. J Hum Virol Retrovirol. 2014;1(3):00018.

18. Chen W, Suan-Sin Foo, Natalie A Sims, et al. Arthritogenic alphaviruses new insights into arthitis and bone patology. Trends in Microbiology. 2015;23(1):35-43.

19. Joy Gardner, Itaru Anraku, Thuy T Le, et al. Chikungunya Virus artritis in adult wild-tipe mice. J. Virol. 2010;84(16):8021-8032.

20. Marion Noret, Lara Herrero, Nestor Rulli, et al. Interleukin 6, RANKL, and osteoprotegerin expression by chikungunya virus: Infected human osteoblast. The Journal of Infectious Diseases. 2012;206(3):455-457.
21. Marques CDL, Angela Luzia Branco Pinto Duarte, AlineRanzolin, et al. Recomendações da Sociedade Brasileira de Reumatologia para diatnóstico e tratamento da febre chikungunya: parte 2. Rev Bras Reumatol. 2017;57(S2):S438-451.

22. Kennedy Amaral J, Peter C Taylor, Mauro Martins Teixeira, et al. The clinical Features, pathogenesis and Methotrexate therapy of chronic Chikungunya arthritis. Viruses. 2019;11:289-300.

23. Sathya Prakash Manimunda, Paluru Vijayachari, Raghuraj Uppoor, et al. Clinical progression of chikungunya fever during acute and chronic arthritic stages and the changes in joint morphology as revealed by imaging. Transactions of the Royal Society of Tropical Medicine and Hygiene. 2010;104(6):392-399.

24. Kam YW, Kwoon-Yong Pok, Kai Er Eng, et al. Sero-prevalence and cross-reactivity of chikungunya virus specifica anti- E2Ep3 antibodies in arbovirus-intected patients. PloS Negl Trop Dis. 2015;9(1):e3445.

25. Smith JL. Human antibody responses to emerging Mayaro virus and cocirculation alphavirus infection examined by using strucutal proteins from nine new and on world lineages. mSphere. 2018;3(2):e000003e00018.

26. Fatih Anfasa, Lisette Provacia, Corine Geurtsvan Kessel, et al. Hiperferritinemia is a potential marker of chronic chikungunya: a retrospective study on the island of Curaçao during the 2014-2015 outbreak. Journal of Clinical Virology. 2017;86(2017):31-38.

27. Sasaki Y, Satoru Manda, Takahiro Sato, et al. Chikungunya vírus infection presenting with persistente arthalgia without fever. Journal of General and Family Medicine. 2015;16(3):204-207.

28. Clémentine Schilte, Frederik Staikowsky, Thérèse Couderc, et al. Chikungunya vírus-associated long-term arthralgia: A 36-month prospective longitudinal study. PLOS Neglected Tropical Disease. 2013;7(3):e2137.

29. Angela Chow, Zhisheng Her, Edward KS Ong, et al. Persistent arthralgia induced by Chikungunya vírus infection is associated with interleikin-6 and granulocyte macrophage colony-stimulating fator. J Infect Dis. 2011;203(2):149-157.

30. Jean-Jacques Hoarau, Marie-Christine Jaffar Bandjee, Pascale Krejbich Trotot, et al. Persistent chronic inflammation and infection by chikungunya artritogenic alphavirus in spite of a robust host immune response. $J$ Immunol. 2010;184(10):5914-5927.

31. Ekaterina Nikitina, Irina Larionova, Evgeniy Choinzonov, et al. Monocytes and Macrophages as viral targets and reservoirs. Int J Mol Sci. 2018;9(19):2821-2849.

32. Sakai Y, Kobayashi M. Lymphocyte 'homing' and chornic inflammation. Pathol Int. 2015;65(7):344-354.

33. David W Hawman, Kristina A Stoermer, Stephanie A Montgomery, et al. Chronic joint disease caused by persistent chikungunya virus infection if controlled by the adaptative immune response. Journal of Virology. 2013;87(24):13878-13888.

34. Thomas E Morrison, Lauren Oko, Stephanie A Montgomery, et al. A mouse model of Chikungunya vírus-induced musculoskeletal inflammatory disease: Evidence of arthritis, tenosynovitis, miositis and persistence. Am J Pathol. 2011;178(1):32-40.

35. Mahmood T, Yang PC. Western blot: technique, theory and trouble shooting. N Am J Med Sci. 2012;4(9):429-434.

36. Teck-Hui Teo, Fok-Moon Lum, Carla Claser, et al. A pathogenic role for CD4+ T cells during chikungunya virus infection in mice. J. Immunol. 2013;190(1):259-269.

37. Aileen Y Chang, Karen AO Martins, Liliana Encinales, et al. Chikungunya arthritis mechanisms in the Americas: a cross-sectional-analysis of Chikungunya arthritis patients tewnty-two months after infection demonstrating no detectable viral persistence in synovial fluid. Arthritis \& Rheumatology. 2017;70(4):585-593. 
38. Jean-Jacques Hoarau, Marie-Christine Jaffar Bandjee, Pascale Krejbich Trotot, et al. Persistent Chronic Inflammation and Infection by Chikungunya Arthritogenic Alphavirus in Spite of a Robust Host Immune Response. J Immunol. 2017;184:5914-5927.

39. Bressan AL, Roberto Souto da Silva, Elisa Fontenelle, et al. Imunossupressores na Dermatologia. An Bras Dermatol. 2010;85(1):922 .
40. Ri F. Mechanism of actionf of hydroxychloroquine as na antirheumatic drug. Semin Arthritis Rheum. 1993;23(suppl 1):82-91.

41. Oumar Faye, Ousmane Faye, Anne Dupressoir, et al. One-step RT-PCR for detection of Zika virus. Journal of Clinical Microbiology. 2009;43:96101. 